\title{
Sportpsychiatric aspects of parasports
}

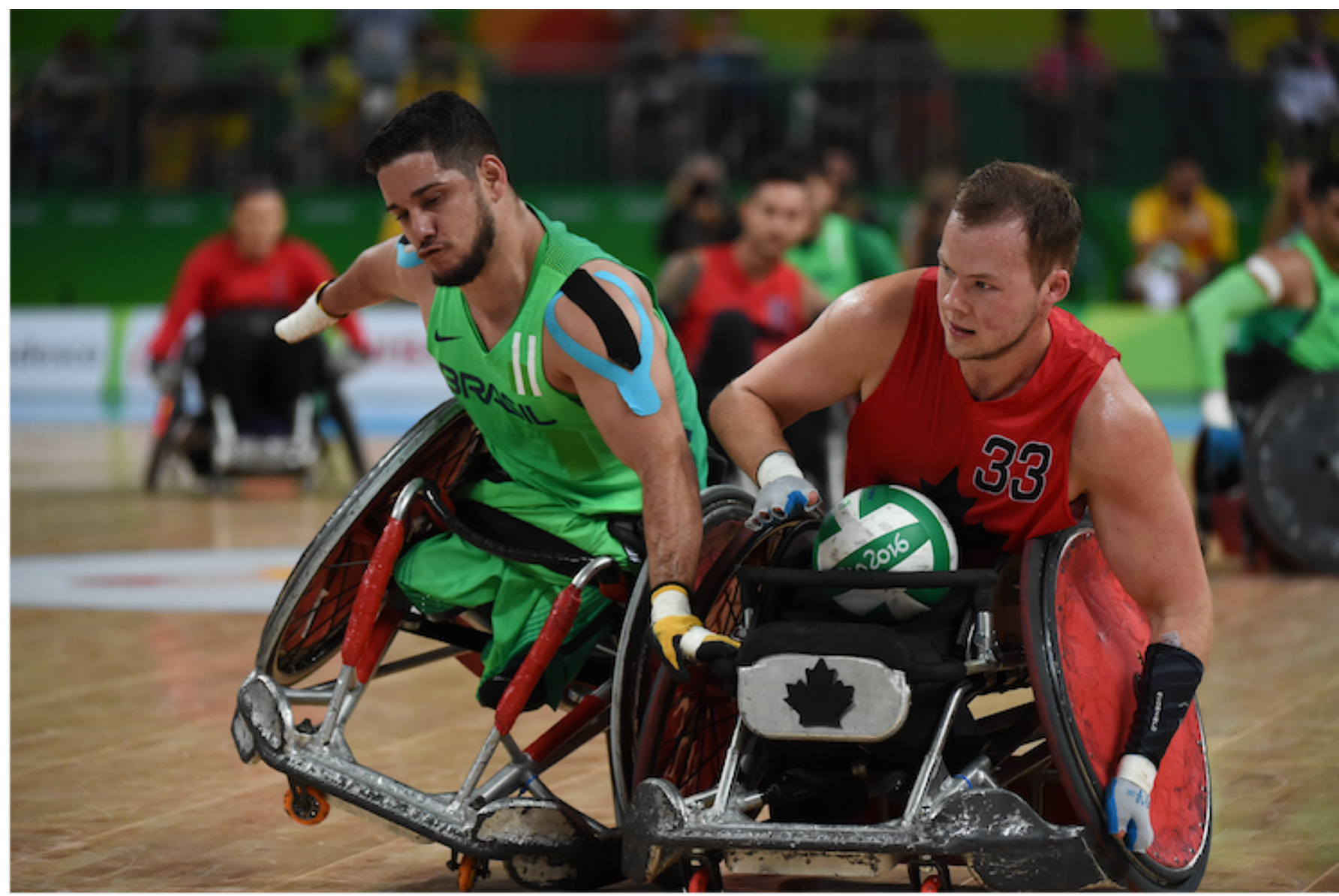

\section{Langer Martina ${ }^{1}$, Jungen Phil ${ }^{2}$, Seifritz Erich ${ }^{1}$, Claussen Malte Christian ${ }^{1,3,4}$}

${ }^{1}$ Department of Psychiatry, Psychotherapy and Psychosomatics, University Hospital of Psychiatry Zurich, Zurich, Switzerland

${ }^{2}$ Swiss Paraplegic Centre, Institute of Sport Medicine, Nottwil, Switzerland

${ }^{3}$ Private Clinic Wyss AG, Münchenbuchsee, Switzerland

${ }^{4}$ Psychiatric Services Grisons, Chur, Switzerland

The Olympic Games tradition dates back to antiquity. And we learned the quote "mens sana in corpore sano est" coming from that period. It became a paradigm in the western world, undermining any efforts of psychiatric relevance in high performance sports. With world renowned athletes himself as suffering from depression, things began to move; nowadays, sport psychiatry has moved from a theoretical option to an 
accepted necessity in elite sports [1]. Nonetheless, there is a remarkable lack of studies on this subject [2]. Taking the taboo out of speaking about psychiatric diagnoses in general, and psychiatric disorders occurring among elite sports specifically, invariably leads to the process that psychiatry is continuously integrated and woven into the network aspect of sports medicine. In consequence, high performance athletes are receptive to this field of expertise.

It is established that there is no difference of the frequency of occurrence of psychiatric disorders between high performance sports and non-sport community. This equally applies for parasports [3,4]. It has shown that specialist psychiatric support seems to be more demanding in parasports. The reasons may be inconsistent and complex. There are even fewer studies concerning psychiatric disorders in parasports, compared to able bodies sports. The leading cause is the persistent stigma of parathletes being mentally disordered "a priori". Understandably, the disabled athletes appose this prejudice. The mental burden of disabled human beings is attributed to exactly this prejudice, and to their social exclusion [2], and not to the fact of their physical handicap in itself. At best handicapped people are applied to be undemanding friendly neuters. Hence, psychiatric studies seem to be superfluous. Handicapped people suffer from the paradox effect of a visible invisibility [5] which again sheds an unattractive view on any scientific consideration. And there remains another contradictory. Disabled people may be sick, neuters, victims, fallen out of life, or whatever - all the more: parathletes are told to be extra extraordinary humans; to overcome a disability in this manner, they simply have to be resilient, tough, and mental healthy heroes. In the end, they are meant to be supercrips [6]. Vice versa, parathletes want to protect their collective. The threshold to admit a psychic problem is even higher than that of abled bodied athletes, because of the mentioned prejudice of being mentally disordered in the first place.

Regarding competition, performance levels and athletic challenge, the paralympic games are developing parallel to the Olympic Games. The classification system is highly specified, even though the categories may not be equitable for every disability. Contrary, there is no real knowledge of the characteristics of psychiatric phenomenons in parasports, of their prevention, diagnosis, therapy and aftercare. The health risk resulting for the parathletes may be evident by the following findings:

- Suicide: Even physicians tend to accept suicide and suicide ideations easier if the client is disabled. They more often ignore or miss the diagnosis of, for example, a treatable depression or other not yet sufficiently treated medical causes [7]. They also may accept risk behaviour as a possible way to get out of an unpleasant life, and miss adequate medical attention and support, including psycho education.

- Conditions: Parathletes may suffer from inappropriate conditions in cramped Paralympic villages, sport venues and recreational possibilities. There may be sleep deprivation and fatigue confused with a severe depression or, even more unfavourable, the other way round. A fatigue and exhaustion sourced by environmental conditions should be addressed as such. The symptoms may be improved by sleeping pills in the night or even stimulants in the day. A mental disorder needs to be treated with psychotherapy and may require psychotropic drugs [8].

Parathletes are often traumatised. High-performance sport is an instrument to cope with this critical life event. Nevertheless, some individuals suffer from a posttraumatic stress disorder. They may try to ignore their symptoms through even higher performance and intensive training. They might evade to focus on the disorder. But they do qualify for high medical attention, and where indicated, medical therapy. It may 
be necessary to reduce sports volume and intensity, one symptom of posttraumatic disorder being a lack of concentration in sports, which leads to drop of performance and/or higher risk of injury [9]. Eventually, paralympic athletes have to give special attention to life after elite sports. They may not be aware of the social and professional changes awaiting them should they be forced to end elite sports due to their physical vulnerability (progressive pathologies) or if they end professional sports willingly. Hence, here is another rather postmodern issue. There are technology developments (e.g. blades) which enable disabled athletes to outdo the abled bodied athletes. That invokes fear. Suspicion a question on viability and its implications on perfection and on humanity.

There is a remarkable need to pay our psychiatric attention on the paralympic athlete. And it is a demanding and interesting need. Physical and psychic subjects are often hardly distinguishable and affected by social and environmental conditions. It should no longer be permitted to ignore disabled individuals and parathletes in their wholeness of humanity and integrity. They still are ignored, underestimated, glorified, and they just want to be normal human beings with all consequences. One of those consequences is the fact of being able to be mentally disordered. And we have to take care not to devote ourselves to this old reserve, the fear to contact disabled individuals, the fear of being confronted with their destiny and with the fact, that this destiny may apply for you, any time.

\section{Corresponding author}

Dr. med. Martina Langer

Department of Psychiatry, Psychotherapy and Psychosomatics

University Hospital of Psychiatry Zurich,

Zurich, Switzerland

martina.langer@pukzh.ch

\section{References}

1. Hainline B, Reardon CL. Breaking a taboo: why the International Olympic Committee convened experts to develop a consensus statement on mental health in elite athletes. British journal of sports medicine. 2019;53:665-666.

2. Swartz L, Hunt X, Bantjes J, Hainline B, Reardon CL. Mental health symptoms and disorders in Paralympic athletes: a narrative review. British journal of sports medicine. 2019;53:737-740.

3. Klenck C, Gebke K. Practical management: common medical problems in disabled athletes. Clinical journal of sport medicine: official journal of the Canadian Academy of Sport Medicine. 2007;17:55-60.

4. Hawkeswood JP, O'Connor R, Anton H, Finlayson H. The preparticipation evaluation for athletes with disability. International journal of sports physical therapy. 2014;9:103-115.

5. Watermeyer B: Claiming loss in disability. in Disability \& Society2009. pp. 91-102.

6. Silva CF, Howe PD. The (In)validity of Supercrip Representation of Paralympian Athletes. J Sport Soc Issues. 2012;36:174-194.

7. Lund EM, Nadorff MR, Samuel Winer E, Seader K. Is suicide an option?: The impact of disability on suicide acceptability in the context of depression, suicidality, and demographic factors. Journal of affective disorders. 2016;189:25-35.

8. Janse Van Rensburg DC, Schwellnus M, Derman W, Webborn N. Illness Among Paralympic Athletes: Epidemiology, Risk Markers, and Preventative Strategies. Physical medicine and rehabilitation clinics of North America. 2018;29:185-203. 
9. Strohle A. Sports psychiatry: mental health and mental disorders in athletes and exercise treatment of mental disorders. European archives of psychiatry and clinical neuroscience. 2019;269:485-498. 